than along it. Afterwards, for a prolonged period, the bottles would remain in the slick spreading out along it but remaining in a narrow line (a slick is typically 1-2 $\mathrm{m}$ wide) and travelling along the slick with the local drift velocity. On some occasions the bottles remained in the slick for 5-6 $\mathrm{h}$ and apparently only left it when the entire slick disappeared in a change of wind. The slicks seemed to be most pronounced and permanent around a wind speed of 5 m.p.h., in May, before the development of the thermocline.

Surface temperature measurements in and near slicks invariably showed a temperature difference of $0 \cdot 5^{\circ}-2 \cdot 0^{\circ} \mathrm{C}$ from one side to the other, often over a very short distance. On one occasion, when strong solar heating was present, the temperature at the centre of the slick was $1.0^{\circ} \mathrm{C}$ higher than on the warmer side. The surface temperatures measured in these observations were between $8.0^{\circ}$ and $14.0^{\circ} \mathrm{C}$. All the observations were carried out within $500 \mathrm{~m}$ from the shore in water 8-10 $\mathrm{m}$ deep.

This communication is published by permission of the Atomic Energy of Canada Limited.

$$
\text { G. T. Csanady }
$$

Assumption University of Windsor,

Windsor, Ontario.

University of Waterloo,

$$
\text { H. K. Ellenton }
$$

Waterloo, Ontario.

Great Lakes Institute,

University of Toronto, Toronto, Ontario.

${ }^{1}$ Richardson, L. F., and Stommel, H., J. Meteorol., 5, 238 (1948),

${ }^{2}$ Batchelor, G. K., Proc. Camb. Phil. Soc., 48, 345 (1952).

\section{A Superconducting Solenoid}

Tests have been made recently on a superconducting solenoid constructed from what is believed to be the longest continuous length of niobium-zirconium alloy wire so far produced in the United Kingdom. An ingot of the alloy (75 at. per cent niobium, 25 at. per cent zirconium) was swaged and cold drawn to give approximately 320 feet of $0 \cdot 010$-in. diameter wire. $100 \mathrm{ft}$. of this was used to construct the coil, which is shown in the accompanying photograph. The insulation was provided by a single layer of silk wrapping round the wire and by sheets of 'Melinex' between the layers of the coil.

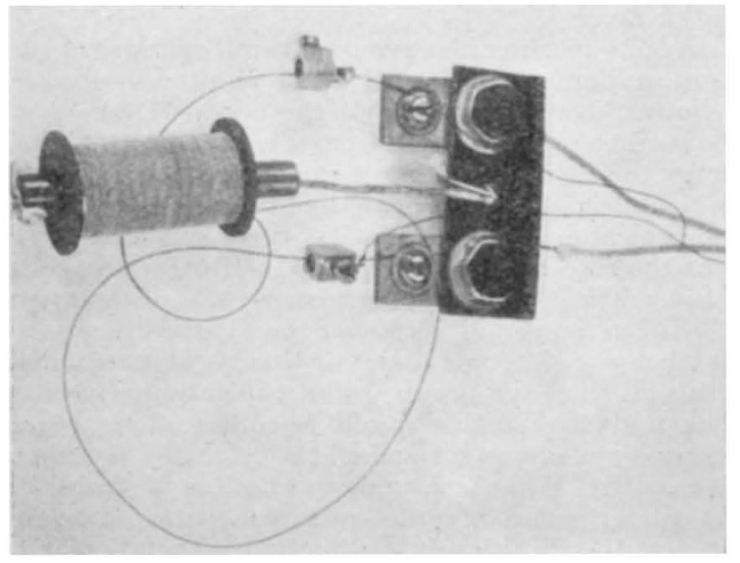

Fig. 1
The coil had the following characteristics: Iengtb of winding, $3 \mathrm{~cm}$; internal diameter, $1 \mathrm{~cm}$; external diameter, $1.6 \mathrm{~cm}$; No. of turns, 992; maximum magnetic field, 382 gauss/amp.

A copper rod was inserted in the centre of the solenoid to absorb the energy released when the coil was driven normal (that is, became resistive). During operation the coil was immersed in liquid helium at $4 \cdot 2^{\circ} \mathrm{K}$.

The maximum current required to drive the wire normal was $23 \mathrm{amp}$; corresponding to a critical current density in the superconductor of $4.5 \times 10^{4}$ $\mathrm{amp} / \mathrm{cm}^{2}$ and a maximum magnetic field at the centre of the solenoid of 8.8 kilogauss. No 'training' effect ${ }^{1}$ was noted during repeated runs. This current density agrees with the values of $5-7 \times 10^{4} \mathrm{amp} / \mathrm{cm}^{2}$ in a field of 10 kilogauss obtained by extrapolating data obtained by Berlineourt ${ }^{2}$ for straight wire specimens of the same composition.

The work described here forms part of an extensive programme, initiated at the Nuclear Research Centre of C. A. Parsons and Co., Ltd., at the beginning of this year, to investigate the fabrication, properties and practical applications of superconductors. Pieces of the wire have been passed to Government and university laboratories for additional tests.

We thank the Directors of C. A. Parsons and Co., Ltd., for permission to publish this communication.

G. W. WIrson

G. M. Мгонт

D. C. Roberts

C. A. Parsons and Co., Ltd.,

Nuclear Research Centre, Fossway,

Newcastle upon Tyne. ${ }^{1}$ Chandrasekhar, B. S., et al., Eighth Intern. Conf. Low Temperature
Physics (preprints, 313) (1962).

${ }^{2}$ Berlincourt, T. G., et al., Phys. Rev. Letters, 6 (12), 671 (1961).

\section{CRYSTALLOGRAPHY}

\section{Anomalous Extinction Effects in X-ray Reflexion by Crystals}

$I_{T}$ is commonly supposed that the effect of the presence of perfect blocks produces a decrease in the intensity of X-ray reflexion from a mosaic crystal. This phenomenon is therefore known by the name of extinction (primary or secondary extinction, according to the conditions of the experiment). However, it appears that this is not necessarily so, and that, under certain conditions, a perfect crystal can give an integrated reflexion which is larger than that of a mosaic crystal. In this case, one would not have an extinction, but an enhancement in the reflected intensity due to the deviation of the crystal from the ideally mosaic state. These results follow from the dynamical theory, in particular from the formula developed by Ramachandran ${ }^{1}$, and have actually been verified in this laboratory using perfect and milky crystals of calcite as representatives of the two extreme limits of perfection.

As is well known ${ }^{2}$, if the reflexion occurs from the surface of the crystal, then it can be shown that the integrated reflexion of a mosaic crystal is larger than that of a perfect crystal and is, in fact, the upper limit under different conditions for the latter. However, for an internal reflexion ('Laue case') the integrated reflexion for a perfect crystal can be much larger than 